\title{
Long-term Ozone Trend Depicted by Ozonesonde Observations over Japan
}

\author{
Fumio Hasebe and Yu Yoshikura* \\ Environmental Earth Science, Hokkaido University, Sapporo, Japan
}

\begin{abstract}
The meridional cross section of the long-term ozone losses between the two periods 1968-1975 (pre-ozone hole era) and 1990-2002 (mature ozone hole era) are estimated by using operational ozonesonde observations over Japan. The results are projected on the bins defined by potential temperature $(\theta)$ and equivalent latitude $\left(\phi_{e q}\right)$ coordinate system to estimate the midlatitude and polar ozone losses separately. The ozone decrease between the two periods are decomposed of 0.3 ppmv $(\sim 5-20 \%)$ decline widely distributed in midlatitude stratosphere and $1.0 \mathrm{ppmv}(\sim 30-50 \%)$ depletion in the focused region defined by $400 \leq \theta \leq 500 \mathrm{~K}$ and $\phi_{e q}>70^{\circ} \mathrm{N}$ during February-April season. The latter gives an estimate of the enhanced ozone loss in the Northern polar vortex, while the former represents general ozone loss in midlatitude lower stratosphere. Atmospheric circulation changes possibly induced by perturbed ozone are discussed in terms of mean $\phi_{e q}$.
\end{abstract}

\section{Introduction}

Stratospheric ozone depletion is one of the first global-scale environmental problems caused by human activities. The range of the ozone loss far exceeds the initial expectation (Molina and Rowland 1974) that was based on gas phase photochemistry initiated by the photodissociation of chlorofluorocarbons. The discovery of the huge ozone decrease in Antarctic spring (Chubachi 1984; Farman et al. 1985) prompted intensive observational and theoretical studies to understand the mechanism of it named later the "Antarctic Ozone Hole." It is now well known to be brought about by catalytic ozone destructions initiated from the activation of halogen species on the polar stratospheric cloud (PSC) surfaces by heterogeneous reactions (Solomon 1990). Such ozone losses are not restricted in the Antarctic. The Arctic losses, though not so huge as compared to the Antarctic, reach such an extent that the circumpolar maximum in the March mean total ozone is replaced by a minimum in the 1990s (Newman et al. 1997).

Anthropogenic ozone depletion is also confirmed in midlatitudes showing maxima in two altitude regions; one in the lower and the other in the upper stratosphere (WMO 2003). Although man-made halogen compounds are commonly responsible for the ozone losses in both layers, the mechanism of activation in the lower stratosphere (LS) is specific in that it strongly depends on the atmospheric burden of sulfate aerosols (Solomon et al. 1996) and increasing amount of water vapor (Dvortsov and Solomon 2001). The estimated loss in Northern midlatitude total ozone in winter/spring is about $4 \%$ in 1997-2001 as compared to pre-1980 averages (WMO

Corresponding author: Fumio Hasebe, Environmental Earth Science, Hokkaido University, Kita-10 Nishi-5, Kita-ku, Sapporo, 060-0810, Japan. E-mail: f-hasebe@ees.hokudai.ac.jp. *Present affiliation: Mazda Motor Corporation. (02006, the Meteorological Society of Japan.
2003). The decreases are not spatially uniform but largest at Sapporo $\left(43^{\circ} 03^{\prime} \mathrm{N}, 141^{\circ} 20^{\prime} \mathrm{E}\right)$ and Canadian stations (Logan et al. 1999). It is, therefore, quite interesting to see the meridional structure of the ozone variations over Japan.

Such ozone losses as well as the accumulation of the greenhouse gases are responsible for the anthropogenic cooling of LS (Ramaswamy et al. 2001), which in turn could cause a delay in the recovery of the ozone hole (Shindell et al. 1998). It is thus quite important to monitor the ozone levels if the expected recovery actually takes place. There are difficulties, however, in the accurate estimation of the chemistry-dependent longterm behavior, as the photochemical lifetime of ozone far exceeds the dynamical time scales in LS. Daily fluctuations of lower-stratospheric (and thus total) ozone are dominated by transport processes, and such ozone variations appear as a large noise in the estimation of the long-term ozone trend. The situation becomes more critical in the analysis of vertical profiles as the operational ozonesonde observations are limited something like once a week or so. The effect of dilution of polar stratospheric air in midlatitudes makes the matter more complicated as the observed ozone trend is a composite of the ozone losses commonly taking place in midlatitudes and those influenced by the dilution of polar "processed" air associated with the polar vortex break down. We need to assess each contribution separately to better understand the long-term ozone variations.

The coordinate system composed of adiabatic invariants, potential temperature $(\theta)$ and Ertel's potential vorticity $(P)$, is convenient to describe ozone variations in LS where its mixing ratio $(\chi)$ is conserved following the atmospheric motion. In this coordinate system, the mixing ratio of inert gases will not change as long as the assumption of adiabatic frictionless motion is valid. In viewing the meridional cross section of the meteorological quantities, $P$ is often converted to equivalent latitude $\left(\phi_{e q}\right)$ to characterize the air parcels (Buchart and Remsberg 1986). Though $\phi_{e q}$ is not conserved even with adiabatic frictionless motions and its fine structure could not be resolved in global mapping in the "surf zone" (McIntyre and Palmer 1983), it provides a convenient framework to identify the origin of the air mass associated with the break down of polar vortex. Randel and $\mathrm{Wu}$ (1995) showed that the midlatitude ozone losses are not solely brought about by the dilution of polar processed air by analyzing the Total Ozone Mapping Spectrometer data on $\phi_{e q}$ coordinates. The present analysis, taking the advantage of long-lasting ozonesonde record by Japan Meteorological Agency (JMA), attempts to estimate the midlatitude and polar ozone losses separately by projecting the longterm stratospheric ozone decrease on $\phi_{e q}-\theta$ coordinates instead of relying on isobars or heights at fixed locations as in the previous studies (e.g., Logan et al. 1999, and references therein). Section 2 describes the data processing procedure, and section 3 illustrates the obtained results. Summaries are put in section 4 together with discussion on meteorological implications. 


\section{Data and analysis procedure}

JMA has been conducting ozonesonde observations at Sapporo, Tsukuba $\left(36^{\circ} 03^{\prime} \mathrm{N}, 140^{\circ} 08^{\prime} \mathrm{E}\right)$, and Kagoshima $\left(31^{\circ} 33^{\prime} \mathrm{N}, 130^{\circ} 33^{\prime} \mathrm{E}\right)$ since 1968 . The instruments used in these stations have been changed from KC-68, KC-79 to KC-96 with major upgrades in 1979 and 1997. The compatibility of the data with those by Electrochemical Concentration Cells (ECC) and others has been studied extensively by intercomparisons (e.g., Logan et al. 1999). There is a difficulty in the exact calibration of each instrument, and the best method for the data screening has been the use of the Correction Factor, $F$, a multiple derived for each sounding to match the vertically integrated ozone amount with independent total ozone measurements. Logan (1994) concluded the range of $F$ for reliable ozone soundings by KC-type instruments being $0.8 \leq F \leq 1.2$. We adopt this criterion in the present analysis for the quality control of the ozonesonde data described below.

Although the dataset is unique in that it provides successive measurements from 1960s, the observation frequency was extremely low during the period from 1975 to 1989 especially in Sapporo and Kagoshima making it difficult to regard it as a time-sequence dataset. Instead of attempting time-series analyses, longterm stratospheric ozone decrease will be estimated by comparing the averages in two periods 1968-1975 (Period I; pre-ozone hole) and 1990-2002 (Period II; mature ozone hole) in the present analysis. The results are illustrated in the difference of the averaged profiles of $\chi$ between the two Periods on the $\phi_{e q}-\theta$ plane. The equivalent latitude at a point $\mathrm{A}$ has been derived by the total sum of the areal segments that have $P$ values larger than that at point A. $P$ has been calculated from the NCEP reanalysis data on each of the isentropic surfaces by using the Stratosphere-Troposphere Research Assisting System (STRAS) provided by National Institute for Environmental Studies (NIES).

\section{Results}

All sounding data that cleared the data screening procedure are used to derive $\chi$ on isentropes by linearly interpolating the temperature and ozone profiles at each station. Then the monthly mean values are calculated for Periods I and II by taking the ensemble mean by each Period. Figure 1 shows the time-height $(\theta)$ sections of the seasonal march of $\chi$ at each station for Periods I (left) and II (center). We can see the spring-time build-up of stratospheric ozone and the ozone decrease associated with the tropopause uplift during summer. The right hand side panel of each diagram is the difference (Period II minus Period I) between the two. General features found there indicate that the ozone in the stratosphere (below 600 or $700 \mathrm{~K}$ isentrope depending on the station) decreased by roughly $0.1 \mathrm{ppmv}$ in the two periods all year round. Though the features are deteriorated by intermittent noise such as the negative values above 560 $\mathrm{K}$ in August in Tsukuba probably by the fluctuations from small sample size in Period I, we can see enhanced ozone depletions that reach $0.4 \mathrm{ppmv}$ or more on the isentropes 440-560 K during March-April in Sapporo, 520-640 K during January-May in Tsukuba, and 600$680 \mathrm{~K}$ in January in Kagoshima. These results are roughly consistent with those obtained on isobaric surfaces (e.g., Logan et al. 1999). The spring-time enhancement of the ozone loss must reflect, at least partly, the advection of ozone-poor air masses processed in the
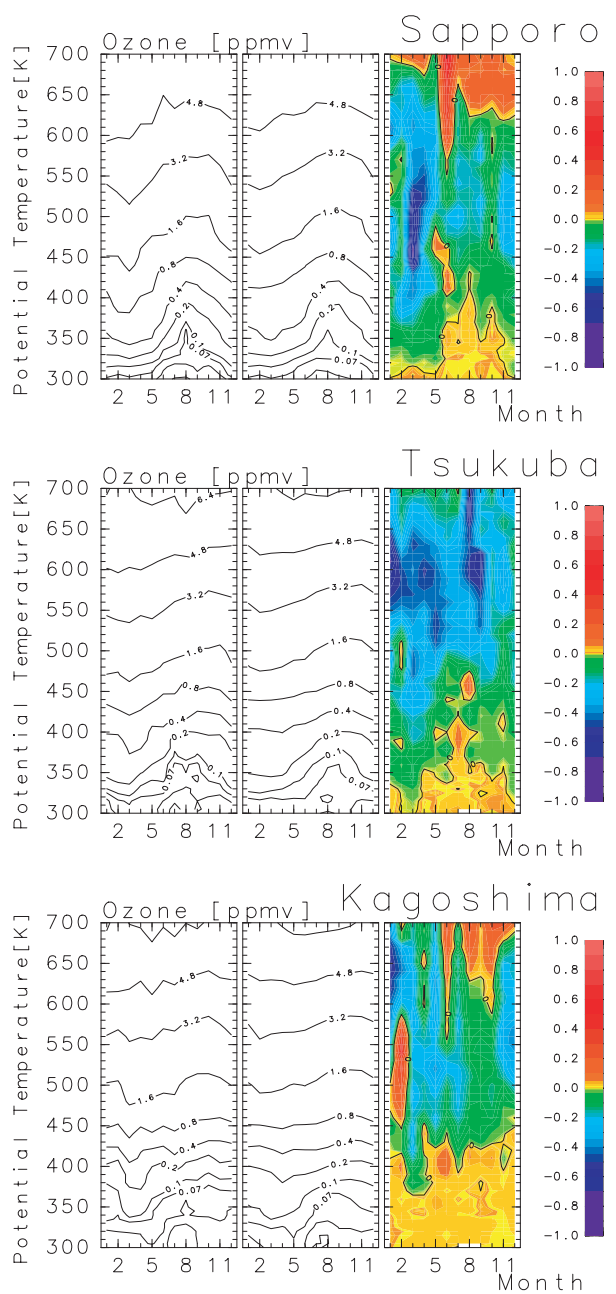

Fig. 1. Seasonal variation of the ozone mixing ratio (ppmv) for the averages of (left) Period I, (center) Period II, and (right) difference (II minus I) over Sapporo, Tsukuba and Kagoshima.

polar region prior to the arrival at midlatitudes in Period II.

For the purpose of characterizing the effect of polar processing on a specific air mass observed in midlatitudes, one can use either $P$ or its equivalence expressed in latitude $\phi_{e q}$. Since we are more concerned with the relative location of the air mass with respect to the polar vortex rather than the strength of the vortex motion itself, $\phi_{e q}$ will be used in the following analysis. Figure 2 illustrates the latitude-height $(\theta)$ sections of the difference (Period II minus Period I) in February-March-April mean values of $\chi$ as derived from the ozonesonde observations over Sapporo, Tsukuba and Kagoshima. The abscissa of the top panel is taken to the geographical latitude with the location of each station marked by its first initials. We can see negative values (long-term decrease) broadly distributed in LS between the isentropes 350 to $650 \mathrm{~K}$. The bottom panel shows the similar diagram except that $\phi_{e q}$ is taken as the abscissa. The difference is calculated by each bin defined with the increment of $7^{\circ}$ in $\phi_{e q}$ and 47 levels in $\theta$ from 300 to $700 \mathrm{~K}$. Moderately negative values in the top panel are dissolved into less remarkable values in the region of low $\phi_{e q}$ and more prominent decrease in LS with high $\phi_{e q}$. The former will represent the ozone decrease 

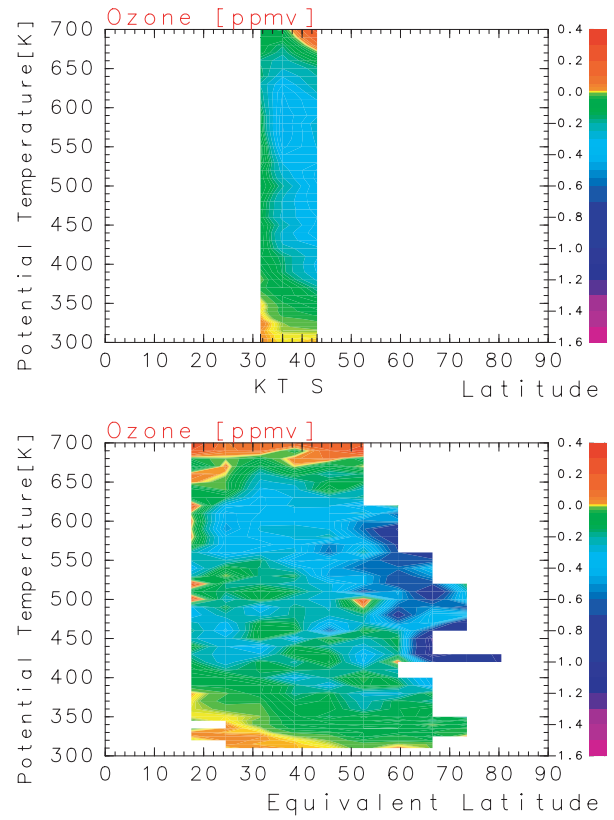

Fig. 2. Latitude-height (potential temperature) sections of the long-term ozone changes (ppmv) expressed by the mean difference between the two periods (Period II (1990-2002) minus Period I (1968-1975)) derived from ozonesonde observations in February, March and April over Japan. Equivalent (instead of geographical) latitude is used in the bottom panel.

commonly occurring in midlatitude LS, while the latter will come from the ozone depletion due to polar processing observed during the excursion of the polar vortex air over Japan. The statistical significance of these results could be seen from Fig. 3, that shows profiles of the mean differences superposed by the confidence intervals of $95 \%$ estimated by using the conventional $t$ values. Over the midlatitude bin $\left(42 \leq \phi_{e q} \leq 49^{\circ} \mathrm{N}\right.$; top), the difference is scarcely significant except for some surfaces near $550 \mathrm{~K}$. However, it turns to be significant on those including 450,500 and $550 \mathrm{~K}$ for the high latitude bin $\left(63 \leq \phi_{e q} \leq 70^{\circ} \mathrm{N}\right.$; bottom), although the uncertainty grows as the number of data decreases.

\section{Summary and discussion}

The long-term stratospheric ozone trend is estimated by using the operational ozonesonde observations over Japan. The results are expressed as the difference in the mean values of the ozone mixing ratio between the periods 1968 to 1975 and 1990 to 2002. By projecting the results on the equivalent latitude $\left(\phi_{e q}\right)$ vs. potential temperature $(\theta)$ coordinates, we could get rid of the strong influence of the transport processes that are dominant in short-term ozone fluctuations at fixed locations. This method is also advantageous in that the observations at a single latitude could cover wide range in $\phi_{e q}$ associated with the deformation of the polar vortex. The ozone decrease thus obtained could successfully decompose the midlatitude ozone decrease into 0.3 ppmv $(\sim 5-20 \%)$ in low $\phi_{e q}$ region $\left(17 \leq \phi_{e q} \leq 52^{\circ} \mathrm{N}\right)$ and 1.0 ppmv $(\sim 30-50 \%)$ in high $\phi_{e q}\left(52 \leq \phi_{e q} \leq 80^{\circ} \mathrm{N}\right)$ lower stratosphere $(400<\theta<500 \mathrm{~K})$ during February-April. The former losses would be attributable to those by midlatitude chemistry such as those activated under the
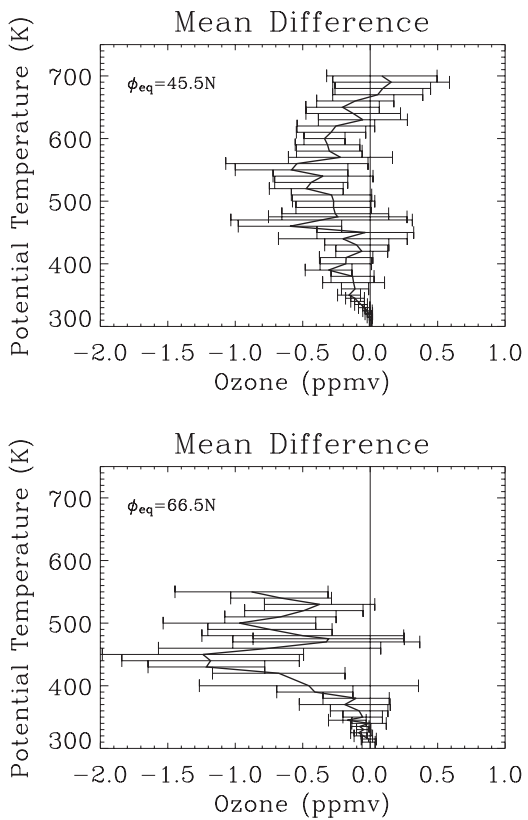

Fig. 3. Vertical profiles of the difference (Period II minus Period I) in the mean values of ozone mixing ratio binned by the equivalent latitude of 42 to $49^{\circ} \mathrm{N}$ (top) and 63 to $70^{\circ} \mathrm{N}$ (bottom) derived from ozonesonde observations in February, March and April over Japan. The bars represent the confidence interval of $95 \%$.

existence of aerosols. The latter, corresponding reasonably to the ozone losses estimated during the spring-time vortex deformation event reported by Nakane (2000), will be the result mostly of polar ozone destruction due to heterogeneous reactions on PSCs, although the weakening of the Brewer-Dobson circulation (Salby and Callaghan 2003) may also contribute.

The introduction of satellite data in 1979 resulted in a significant change in the NCEP reanalysis temperature field (Santer et al. 1999) especially above $200 \mathrm{hPa}$ and south of $50^{\circ} \mathrm{S}$ (Kistler et al. 2001), making it inappropriate for the data to be used in the study of multidecadal variability of the tropical tropopause (Randel et al. 2000). It is not readily available how the potential vorticity $(P)$ and equivalent latitude fields are affected by the change, although there found no evidence of an abrupt change in 1979 in the time series of $\phi_{e q}$ over the three stations analyzed here. As the distribution of $\phi_{e q}$ is mostly described by the planetary scale $P$-fields, there will be a reasonable hope that its gross features could be captured by the radiosonde network even in the pre-satellite era. However, we need to be cautious about the limitation of our results, since much of them depend on the NCEP reanalysis field.

The ozone mixing ratio at a fixed location averaged during a period, $\chi(\phi)$, is determined by the average of those values of air parcels that cover the location during the period. If the averaging time is enough short so that the ozone mixing ratio at $\phi_{e q}$ could be regarded as a constant value of $\chi\left(\phi_{e q}\right)$, we have

$$
\chi(\phi)=\sum_{\phi_{e q}} p_{\phi}\left(\phi_{e q}\right) \chi\left(\phi_{e q}\right)
$$

where $p_{\phi}\left(\phi_{e q}\right)$ is the probability that latitude $\phi$ is covered by the air mass characterized by $\phi_{e q}$. If the long-term 


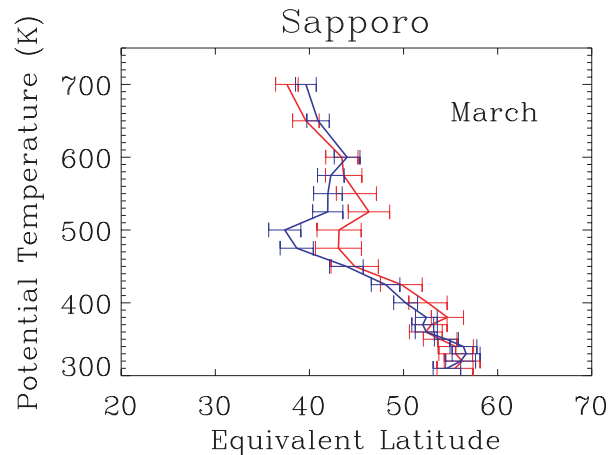

Fig. 4. Vertical profiles of mean equivalent latitude over Sapporo in Period I (red) and Period II (blue) with error bars of $99 \%$ confidence intervals.

perturbations are so small that their products are neglected,

$$
\Delta \chi(\phi)=\sum_{\phi_{e q}}\left\{p_{\phi}\left(\phi_{e q}\right) \Delta \chi\left(\phi_{e q}\right)+\Delta p_{\phi}\left(\phi_{e q}\right) \chi\left(\phi_{e q}\right)\right\}
$$

where $\Delta$ denotes perturbations. Figure 2 was the result of our attempt to estimate $\Delta \chi\left(\phi_{e q}\right)$ (bottom) by reassembling the data used to draw $\Delta \chi(\phi)$ (top).

The problem left untouched is the contribution due to the change in circulation properties expressed as $\Delta p_{\phi}\left(\phi_{e q}\right)$. One of such aspects can be viewed by comparing the mean value of $\phi_{e q}$, that is, $\phi_{e q}(\phi)=\sum p_{\phi}\left(\phi_{e q}\right) \phi_{e q}$ for the two periods. An example is shown in Fig. 4 that illustrates the vertical profiles of $\overline{\phi_{e q}}$ over Sapporo with the estimates of $99 \%$ confidence intervals. The calculation is based on daily NCEP reanalyses irrespective of the availability of ozonesonde observations to improve statistical significance. We could see highly significant difference between the two periods on the isentropes between 475 and $550 \mathrm{~K}$. The decrease of $\phi_{e q}$ from Period I to II is brought about by the decrease of $p_{\text {sapporo }}\left(\phi_{e q}\right)$ for $\phi_{e q}>35^{\circ} \mathrm{N}$ (not shown). It is quite interesting to see that these isentropes correspond to the region that the ozone depletion due to polar processing is most influential over Japan. If this is an indication of the polar vortex stabilization, e.g., Nakane (2000), due to the depleted ozone-induced cooling of the polar lower stratosphere, it may imply that the polar stratospheric ozone depletion would be less severely observed over Japan due to the feedback from chemistry to dynamics. Further analyses are underway, and the results will be published elsewhere.

\section{Acknowledgments}

The main part of the present results comes from the M.S. Thesis of YY submitted to Graduate School of Environmental Earth Science of Hokkaido University in February 2005. We wish to express hearty gratitude to the members of Division of Ocean and Atmospheric Sciences especially to E. Tanaka for discussion, to K. Misumi for drawing figures, and to K. Yamazaki and M. Fujiwara for helpful comments. Comments from anonymous reviewers are also appreciated. We are much grateful to H. Nakane of NIES and I. Ikeuchi of Fujitsu FIP for making STRAS available. This work has been partly supported by 21st Century COE program, "Prediction and avoidance of an abrupt change in the bio-geosphere system."

\section{References}

Butchart, N., and E. E. Remsberg, 1986: The area of the stratospheric polar vortex as a diagnostic for tracer transport on an isentropic surface, J. Atmos. Sci., 43, 1319-1339.

Chubachi, S., 1984: Preliminary result of ozone observations at Syowa station from February 1982 to January 1983, Mem. Natl. Inst. Polar Res., Spec. Issue No. 34, Proc. Sixth Annual Symp. Polar Meteorology and Glaciology, 13-19, Natl. Inst. of Polar Res., Tokyo, Japan.

Dvortsov, V. L., and S. Solomon, 2001: Response of the stratospheric temperatures and ozone to past and future increases in stratospheric humidity, J. Geophys. Res., 106 (D7), 7505-7514.

Farman, J. C., B. G. Gardiner, and J. D. Shanklin, 1985: Large losses of total ozone in antarctica reveal seasonal $\mathrm{ClO}_{x} /$ $\mathrm{NO}_{x}$ interaction, Nature, 315, 207-210.

Kistler, R., E. Kalnay, W. Collins, S. Saha, G. White, J. Woollen, M. Chelliah, W. Ebisuzaki, M. Kanamitsu, V. Kousky, H. van den Dool, R. Jenne, and M. Fiorino, 2001: The NCEPNCAR 50-year reanalysis: Monthly means CD-ROM and documentation, Bull. Amer. Meteor. Soc., 82, 247-267.

Logan, J. A., 1994: Trends in the vertical distribution of ozone: An analysis of ozonesonde data, J. Geophys. Res., 99, 25553-25585.

Logan, J. A. et al., 1999: Trends in the vertical distribution of ozone: A comparison of two analyses of ozonesonde data, J. Geophys. Res., 104, 26373-26399.

McIntyre, M. E., and T. N. Palmer, 1983: Breaking planetary waves in the stratosphere, Nature, 305, 593-600.

Molina, M. J., and F. S. Rowland, 1974: Stratospheric sink for chlorofluoromethanes: chlorine atom-catalysed destruction of ozone, Nature, 249, 810-812.

Nakane, H., 2000: Long and short term variability in the dynamical attributes of the Arctic polar vortex and its effect on ozone, SPARC Newsletter, 15, 15-17.

Newman, P. A., J. F. Gleason, R. D. McPeters, and R. S. Stolarski, 1997: Anomalously low ozone over the Arctic, Geophys. Res. Lett., 24 (22), 2689-2692.

Ramaswamy, V., M.-L. Chanin, J. Angell, J. Barnett, D. Gaffen, M. Gelman, P. Keckhut, Y. Koshelkov, K. Labitzke, J.-J. R. Lin, A. O'Neill, J. Nash, W. Randel, R. Rood, K. Shine, M. Shiotani, and R. Swinbank, 2001: Stratospheric temperature trends: Observations and model simulations, Rev. Geophys., 39, 71-122.

Randel, W. J., and F. Wu, 1995: TOMS total ozone trends in potential vorticity coordinates, Geophys. Res. Lett., 22 (6), 683-686.

Randel, W. J., F. Wu, and D. J. Gaffen, 2000: Interannual variability of the tropical tropopause derived from radiosonde data and NCEP reanalyses, J. Geophys. Res., 105, 1550915523.

Salby, M. L., and P. F. Callaghan, 2003: Systematic changes of stratospheric temperature: Relationship between the tropics and extratropics, J. Geophys. Res., 108 (D3), 4101, doi:10.1029/2001JD002034.

Santer, B. D., J. J. Hnilo, T. M. L. Wigley, J. S. Boyle, C. Doutriaux, M. Fiorino, D. E. Parker, and K. E. Taylor, 1999: Uncertainties in observationally based estimates of temperature change in the free atmosphere, J. Geophys. Res., 104 (D6), 6305-6333.

Shindell, D. T., D. Rind, and P. Lonergan, 1998: Increased polar stratospheric ozone losses and delayed eventual recovery owing to increasing greenhouse-gas concentration, Nature, 392, 589-592.

Solomon, S., 1990: Antarctic ozone: Progress towards a quantitative understanding, Nature, 347, 347-354.

Solomon, S., R. W. Portmann, R. R. Garcia, L. W. Thomason, L. R. Poole, and M. P. McCormick, 1996: The role of aerosol variations in anthropogenic ozone depletion at northern midlatitudes, J. Geophys. Res., 101, 6713-6727.

World Meteorological Organization, 2003: Scientific Assessment of Ozone Depletion: 2002, Report No. 47, 498 pp., WMO Global Ozone Research and Monitoring Project.

Manuscript received 3 March 2006, accepted 19 May 2006

SOLA: http://www.jstage.jst.go.jp/browse/sola/ 